\title{
An Assessment of the Materials Used for the Preparation of Traditional Medicine by Traditional Medical Practitioners in Nigeria
}

\author{
Bilkisu Lawal $^{1}$ and Mohammed Tukur Lawal ${ }^{2}$ \\ ${ }^{1}$ Department of Library and Information Science, Umaru Musa Yar'adua University Katsina, Nigeria \\ ${ }^{2}$ Research Scholar, Department of Library and Information Science, SRM University, Sonepat, Haryana, India \\ E-mail: sayayabilkisu@gmail.com,mohammed.tukur@umyu.edu.ng
}

\begin{abstract}
This research was conducted to assess the materials used for the preparation of traditional medicine by traditional medical practitioners in preparing traditional medicine in Nigeria and a case study design was employed to investigate the phenomena. The study also used a purposive sampling technique, specifically convenience sampling to select participants and unstructured interview was used to collect data from the participants. A manual thematic analytical approach was done, which yielded a total of 309 codes and grouped together to form 11 sub-categories, the 11number of sub-categories were narrowed down to into 5oversearching themes(wider categories) the 5 emergent themes were narrowed down into 3 theoretical constructs. The findings from the study indicated that the Traditional medical practitioners use Biological- herbs, and Special Quranic prayers to cure diseases even though there is no formal documented information on traditional medical practice. The traditional medical practitioners visiting bushes, plucking of leaves, uprooting relevant plants for their stems and roots, cutting trees, and peeling of tree skins as primary aspect of the procedure while the secondary Procedure covers washing, cleaning, drying, chopping, pounding, packaging and preserving. In conclusion, documenting traditional medical knowledge was considered the most important factor that would encourage and patronizes these of the medicine and the ascendants' of the traditional medical practitioners to continue with the practice. It was therefore recommended that in order to improve the use of traditional medicine and its heritage there is the need for proper documentation.
\end{abstract}

Keywords: Documentation, Assessment, Medicine, Medical Practitioners, Traditional Medicine, Medical Knowledge

\section{INTRODUCTION}

Much attention has been accorded to and researches are being carried out on Traditional medicine knowledge, especially in recent times. Due to particularly the global health care demand and the significant role of traditional medicine in meeting the public health needs of rural populace in developing countries. Documenting and protecting these medicines are becoming a greater priority (Abbott, 2014).

Documenting Traditional Medicine Knowledge helps in preserving the knowledge. Today, the cultural survival of many indigenous communities is threatened, and some traditional systems of disseminating information may be lost. Modern lifestyles and the disruption of traditional ways of life, cause younger generations to lose interest in learning traditional medicine practices. Traditional languages used to pass information is no longer widely used and understood as before. Therefore, documenting Traditional Medicine Knowledge may help preserve this knowledge for future generations, Abbott (2014). Similarly, documenting traditional medicinal knowledge may also improve the use of traditional medicine and can be a vital step in facilitating research on traditional medicine safety and efficacy. In addition, the documentation may assist with clinical practice and teaching. Looking at the important role traditional medicine plays in providing health care, documenting Traditional Medicine Knowledge may help improve public health. Documentation may also promote commercialization of Traditional Medicine Knowledge. In this respect, it is necessary to ensure proper documentation which may help Traditional Medicine Knowledge holders to market traditional medical-based products and services (Abbott, 2014).

Akintilo, (2000) asserts that traditional medicine is part of the people's socio-cultural milieu and that it conforms to the basic tenets of 'Primary Health Care' as advocated by the World Health Organization. Knowledge in local community is closely related to wisdom and the ultimate goal of seeking knowledge is to make one wise to acquire relevant experience on how to live profitably within the community. The process of knowledge acquisition among the local community requires one to be courageous, humble and hardworking. He must be diligent, obedient and respectful of his master and elders in the community. Knowledge acquisition in local community is targeted at preparing one to face the present and future challenges in the society. Yet, there is no curriculum as in Western knowledge system which is acquired within the confine of serene environment based on expected or predetermined outcome. In Hausa community knowledge is pursue and not acquired because one is expected to assimilate and properly blend into the culture before he can understand what he is expected to learn. Reality in traditional society is shaped by cultural practices and before one can understand the practices he must believe it and assimilate it before he can blend in the culture. Traditional practices in communities according to 
Madauchi, et al., (2008) include trades and crafts such as blacksmith and iron smelting, building, butchery, farming and hunting, fishing, animal husbandry, medical practices and many other professions.

The traditional medicine practitioner as defined by the WHO (1976) is a person who is recognized by the community in which he lives as competent to provide health care by using vegetable, animal and mineral substances and certain other methods based on the social, cultural and religious background, as well as on the knowledge, attributes and beliefs that are prevalent in the community, regarding physical, mental and social well-being and the causation of disease and disability

\section{LITERATURE REVIEW}

\section{A. Concept of Indigenous Knowledge}

There are different concepts of Indigenous knowledge and the differences may be due to differences in culture and motivation of scholars who conceived the term. As the result of the differences in the conception of the term various assumptions; metaphysics, epistemologies, and values of Indigenous knowledge have been produced. Accordingly Battiste and Henderson (2000) defined the term Indigenous to mean "the descendents of the first people to inhabit a locality.” By this Indigenous people can be collectively identified as belonging to a particular group or locality and can be recognized by other groups or by state authorities as being distinct due to their origin.

The group can also strive to perpetuate their cultural distinctiveness in spite of influence of modernization and suppression by other groups to assimilate in to their cultures. Furthermore, Niezen (2003) added that people may be called Indigenous people because they have collective experiences of oppression, marginalization, economic servitude, and socio-cultural problems.

Western countries have for years being marginalizing Africa to the level that anything from Africa is undervalued, made to become underprivileged and underrepresented. This view was echoed by Ocholla (2007) who identified that today, the more a community possesses or practices Indigenous knowledge, the more the community is marginalized or stigmatized. This is the view of Western scholars who believed that anything they cannot understand is falsehood and magical and should be suppressed or oppressed and marginalized to prevent it from spreading. However, what is important about most Indigenous knowledge is they represent culture and that it is the culture of the people that can be used in the development of local communities. Thus, indigenous knowledge is still relevant in the modern times and it should be documented to enhance its access to the people that may need it.

The Hausa referred to knowledge as [il'mi] meaning a lifelong experience which one pursues actively and vigorously earn to make a living. Equally, a popular Hausa saying outlined the difficulties in pursuit of knowledge by referring to the process of acquiring knowledge as [nazangi moriyarka da nisa]. Meaning that, the benefit of knowledge is far or distant because it does not come easily. Hausa parent send their children to faraway places to pursue knowledge. Equally, added that knowledge in Hausa is closely related to wisdom as its ultimate goal is to make one wise to acquire relevant experience on how to live profitably within the community. They maintained that knowledge gives one the opportunity to earn comfortable living standard, gain admiration, and acceptance in the community. Hausa believe that to earn knowledge one has to undergo hardship of deprivation, love and affection of the family and kinsmen. Some children often become destitute in the process to gain knowledge. The process of knowledge acquisition among the Hausa also requires one to be courageous, humble and hardworking. He must be diligent, obedient and responsible to his master and elders in the community before he can be given the right knowledge. This is because knowledge acquisition in Hausa is targeted at preparing one to face the present and future challenges in the society. Yet, there is no curriculum to guide the teaching and learning process as in Western knowledge system which is acquired within the confine of serene environment based on expected or predetermined outcome.

\section{B. Traditional Medical Practice in Nigeria}

Nigerians have a deep belief and reliance on the services of the traditional practitioners for their health care needs. An estimated 75 percent of the population still prefers to solve their health problems by consulting the traditional healers (Adam, 2008), Nigerian Tribune, (March 2008).

Olowu, (2004) posits that traditional medical practitioners acquire herbal knowledge either through inheritance or apprenticeship as a call bygone or the other. In the past, many of them practiced the art as a hobby or as a form of community service with little or no financial rewards thus making the practice "pure and efficacious". Traditional medical practice system is well structured and organized and has survived through generations to maintain harmony between body, mind and soul within its socio-cultural and religious context. The various ethnic groups in Nigeria have different traditional healthcare practitioners aside their western health care counterparts. The Yoruba call them 'Babalawo', the Igbo call them 'Dibia', while the Hausa refer to them as 'Boka'.

However, different experts have emerged within their ranks including herbalists, bone-setters, psychiatrics, and birth attendants, among several others. They usually rely on vegetables, mineral substances, animal parts and certain other methods such as prayers, divinations and incantations Oluwo and Jerome, (2004). Traditional medicine has impacted significantly on the lives of the people especially in the rural areas where access to orthodox Medicare is minimal. Aside the lack of access, the prohibitive cost of western medications makes traditional medicine attractive. 


\section{Impact of Information and Communication Technology (ICT) in Documenting Traditional Medical Information}

According to Adam (2009) information and communication technologies play major roles in improving the availability of traditional knowledge systems and enhancing its blending with the modern scientific and technical knowledge. The Traditional Medical Practitioners in Matazu Local Government Area of Katsina State can adopt the modern treads in traditional medical practices for example the use of Media (Print and Electronic). Use of Information and Communication Technology ICTs which includes telecommunications technologies such as telephony, mobile phones, cable, satellite and radio, as well as digital technologies, such as computers, information networks and software. The new information and communications technologies such as computers and the Internet can help generate wealth and jobs, build bridges between governments and citizens, forge relations among organizations and communities, and improve the delivery of essential services to poor people.

\section{Objectives of the Study}

1. Find out the materials used for the preparation of traditional medicine by the practitioners in Nigeria.

2. Identify the types of knowledge documentation practices employed by the traditional medical practitioners

3. Determine the search skills and procedures used by the traditional medical practitioners in preparing traditional medicine

\section{METHODOLOGY}

There are basically three types of research methodology that is qualitative, quantitative and mixed. The researcher adopted qualitative research methodology. Qualitative research methodology, according to Denzin and Lincoln (2003. The researcher chooses qualitative research as a paradigm that would facilitate this purpose. Qualitative method is ideal because it is effective in the study of behavior and behavior changes. It aims to gather an in-depth understanding of human behavior and the reasons that govern such behavior (Denzin, \& Lincoln, 2002).

The researcher adopted qualitative research because it is suitable for the research. It allows experiences to be presented, a private feeling expressed, and employs the process of trust building. It appreciates the holistic manner of life including social aspect, cultural aspects (traditional health belief, values, norms believes) life style and behavior, which quantitative research cannot do as well.

\section{A. Population of the Study}

According to Ifidon, and Ifidon, (2007) define population as generally a large collection of individuals or objects that is the main focus of a scientific query. Similarly, Hassan
(2013) defines research population as a well-defined collection of individuals or objects known to have similar characteristics. All individuals or objects within a certain population usually have a common, binding characteristics or trait. It is for the benefit of the population that researches are done. The population of this study comprised all the traditional medical practitioners in Nigeria sampled by the researcher. The total number of the registered traditional medical practitioners as a mini project the total number of respondents selected is

\section{RESULTS AND DISCUSSION OF FINDINGS}

\section{A. Materials for Preparation of Traditional Medicine}

This sub-category provides some explanations quotes from the participants' responses on ingredients used for treatment of common diseases. It is also provide explanations of each diseases with the ingredients used for treatment of the diseases, as detailed by these respondents: "for diseases like pile there is sauyar 'kurukuru' prepared with offal, water, magi star, ginger, cooked with exception of salt, pepper, and onion "other respondents explained that there are two types of malaria which can be treated by the following ingredients:" first type of malaria, one will look for turare leaf (tree), paw-paw leaf cooked together, extract boiled water from the cooked herbs and inhale the vapour".

"for malaria yellow fever (jaundice), mango trunk peels, its green leaves cooked with water and taken morning and night. It replenishes blood.”Furthermore, another respondent expressed that, "for headache one will look for 'tumpapiya' leaf, cook it and inhale the boiled vapour."For diseases like stomach ache this respondent voiced that; we look for 'kwandari' its leaf will be cooked and three spoons of its syrup will be taken morning, day and night”. For Asthma the respondents confirmed that; I occasionally administer it. I used a herb called 'kokiya' and 'ganya' and recite verse of the Holy Qur'an called 'Iklas' three times and then pound them together and sieve it. It should be soaked in water and lightly taken. The solid waste of the herb that settles down the container will be extracted and a bit of groundnut oil should be added to it and should subsequently be used by sprinkling the substance on burning charcoal to spark fumes that will be mildly inhaled by the individual (asthmatic).

For ulcer a respondent ascertained that: "there are two types of medicines to its treatment number one there is 'bijiyoji' added to this and that, pound together and sieved. three (3) table spoons of the powder should be fetched and divided into six (6), 1/6 of the powder plus 1 egg and half of liquid tin milk should stirred together taken morning, day and night for four days. -ulcer patient can eat pepperish food there will be no stomach crisis" Additionally, another respondent further expressed that "Medicine for ulcer number two, one can get peels 'dakwara' (a tree), its leaf, pound them together. Three table spoons should be fetched and divided into six, 1/6 should be taken with half of liquid 
tin milk morning, day, and night with exception of egg, after four days the patient will be fine even if the ulcer is chronic"

Accordingly, a respondent mentioned and described materials used for treatment of Sickle cell anemia; "the medicine for it is 'khulba' oil and honey mixed together one table spoon be taken morning, afternoon and night then the patient will apply 'habatussauda' oil on his skin even before the sickle cell anemia crisis begins. The respondents further added that.....to habatulsuada oil, there is a prayer that is recited on it. It is "Bismillahi" three times as well as "Allahumma bi izzatilahiwaqutini $\min$ sharriajiduwaqarahu" should be recited seven times on the habatussauda applied on the skin of the patient until it finishes.Another respondent added that:; the medicine forsickle cell anemia it is 'khulba' oil and honey mixed together one table spoon be taken morning, afternoon and night then the patient will apply 'habatulsauda' oil on his skin even before the sickle cell anemia crisis begins. The respondents further added that..... tohabatulsuada oil, there is a prayer that is recited on it. It is "Bismillahi" three times as well as "Allahumma bi izzatilahiwaqutini $\mathrm{min}$ sharriajiduwaqarahu" should be recited seven times on the habatulsauda applied on the skin of the patient until it finishes.

For a disease like Hiccup this respondents revealed that "cow fat placed on paper (typical cement paper) place the paper with cow fat in it on a mildly burning fire. As soon as it melts scoop it into a container and then ask the person suffering of hiccups to use one of his fingers to absorb it into his mouth”.

Accordingly, the medical practitioners further explained the materials for the treatment of diseases like, infertility and miscarriage, HIV/AID, Gonorrhea, tooth ache, hiccup, diabetes, dizziness, epilepsy, hepatitis B. below are some of their responses:

For infertility and miscarriage“ I administer khulba powder. For instance if the pregnancy is three months old she would fetch one spoon of it and cook it in water and pour in a big bow and sit in it repeat the same thing in the fourth, fifth and sixth months”.

For the HIV/AIDS;"what we use to prepare its concoction are hand powder and sauyar zogale (moringa root) peal it until it reveals the whitish part of it and then add it to hand powder and pound them together. Patient's blood will be tested to ascertain the severity of the diseases.

If the severity is high, the patient will be given three (3) weeks dose More than 20 HIV patients were cured of the disease For the treatment of Gonorrhea; "for it too, we use moringa root (sauyar zogala), 'chindazugo' root and red potassium add them up together in a pot with water and allow it boil a bit. Taken for four (4) days consecutively”
For the treatment of tooth ache: "there is 'kal' syrup. Three spoonful of it will be taken and two spoonful of honey and one small spoonful of salt and then mix them up. Stick a finger in the syrup and apply to the aching tooth and behold the aching will be gone. As for the prayer, fatiha (opening chapter of the Holy Qur'an) will be recited three times and at end of the recitation of each fatiha the patient will respond by saying Amin (i.e 3x) after which the recite will say relieve with the permission of Allah. The pain or ache persist ask him to hold the aching tooth again and re-recite Fatiha two times. Allah willing the aching will subside.”For the treatment of disease like, hiccup; "we get cow fat and place on a paper (typical cement paper) and place the paper with cow fat in it on a mildly burning fire as soon as it melt scooped it into a container and then ask the person suffering of hiccups to use one of his fingers to absorb it into his mouth. Allah willing he will be cured of hiccups" Also for the treatment of diabetes; "there is a vegetable called 'shuwaka' (bitter leaf) their roots is what we get and tie together and poured in a pot and add red potassium and water. The syrup will be used to make gruel using red guinea corn and taken for two days. Each day, fresh preparation, the diabetic patient to go to hospital for check up, this is done to ascertain the level of the diabetes. I don't want the diabetic patient to take the concoction beyond two days so that the sugar level in the blood will not go down beyond measure, cured many diabetic patients with the concoction."For the treatment of dizziness; "one will use a dry chunk of "tumpapiya" tree and cut it into smaller pieces and add to burning charcoal and inhales the smoke arising thereby, Allah willing never have episode of dizziness again. The same thing for "juwa" (a sickness related to dizziness)”

More so, for the treatment of epilepsy these respondents enlightened that; "we use only one single herb from a tree called 'namijin kanya'. The herb will be fetched from the tree by way of peeling from four (4) different spots then pound them and get it dried in the sun, don't make into complete powder. The next thing is the epileptic person will bring black coloured hen then the medicine will be given to the person to go and do the rest or better still I will collect the hen from him slaughter it, clean it up, and pour the medicine in a pot in addition to the cleaned hen and cook with only magi added.

When it is done cooking, the bones and meat will be extracted apart. The sick or the epileptic person will completely eat the meat, and then the bones including the hen's legs and head and the cooked herbs will be dried and pounded. It will be sprinkled on burning charcoal to produce fumes until it finishes every day". Another respondent further explained that, for the treatment of disease like, Hepatitis B:"we use herbal concoction of 'kaltuppa' and honey balanced equation in quantities of 'kaltuppa' and honey taken twice daily Hausa traditional solid sugar dissolve in water and taken as water for two days dosage. 


\section{B. Ingredients for Treatment of Jinnu/spiritual illness}

This sub-category provides some explanations quotes from the participants' responses on ingredients used for treatment of junnu/spiritual illness. It is also provide explanations of diseases with the ingredients used for treatment, as articulated by these respondents. "For jinn, exorcism and spell rukiyyah a special Quranic recitation prayer is rendered. Using a combination of zafran, miski, to prepare ointment to ward off evil eyes away from new born Ointment so effective to render evil doer powerless to the point of getting out of mosque for instance or confess talks about spell as a hindrance to one's ability to stand and walk and the ability to make that individual regain his agility through prayers A kind of eye disease 'Hakiya' (cataract) using bagaruwa (a tree) leaf, grinding it and dry Further preparation of bagaruwa leaf and application to the affected eye by a way of drops in the eye. Dosage of 'bagaruwa' eye drop"Another respondent further elucidated that: "I do rukiyyah (prayer magic) for spiritual medication from Jinn, Madness, and the rest and i pray to Allah for success" Other material worthy of note is earth. One respondent unequivocally said for treating infertility "I fetch sand of any kind within my reach and pray over it and give to the individual (female)... The individual will return after putting to bed to appreciate my effortthe sand will be soaked in a bow with water and taken for one week.

\section{Method of Knowledge Documentation}

This category contains traditional medical practitioners' responses that elaborate the process of knowledge documentation practices employed by the traditional medical practitioners in Nigeria. It also shows narratives explaining the type of knowledge documentation practices employed by the traditional medical practitioners. It is generated from three main sub-categories.

1. Published books on diseases and herbal cure.

2. Manuscript and Knowledge inheritance.

3. Knowledge Stored in brain.

\section{Published Books on Diseases and Herbal Cure}

Responses from traditional medical practitioners indicated that one of the ways of documenting knowledge is through texts published by our leaders or members as expressed by the following respondents: "there are texts published by our leaders and the ones published by our members that contain explanations in great details" similarly, another respondent further voiced that:"We don't give our books to voodoo practicing individuals because the books carry Quranic Verses" Another respondent who has never publish a book and have intention to publish said that: "I have intention to publish my methods of concoction for all the ailment and diseases as well as prescription and dosage because there is no member that has published a book". The respondents further mentioned two of their members that published books”

\section{E. Manuscript and Knowledge Inheritance}

This sub-category provides some explanations quotes from the participants' responses on the knowledge in written form in case death occurs, as explained by these respondents: "we generated knowledge in written form which we personally penned down in case something bad happens or death occurs to me". In the same vein another respondent further said: "I have the knowledge in my head as well as in written form which i for myself kept it for my family in case something bad happens to me."Furthermore these respondents detailed that: "Truly, the way we follow for the documentation of our knowledge is on exercise book for our own benefit only. When our children grow they can look at and understand what we use in making the herbal medicines, we don't do it for public consumption because it is an inherited practice. It is a must that the information is for you, your children, friend or someone you trust. They are the ones that will know your formula. Truly, that's how it is.

Other respondents expressed that they kept knowledge for their children to inherit when they are not alive. These are their stories on their own words: "we all have children who has taken after our footsteps and even prepares medicines....this respondent further said, "My children are twelve (12) in number and only two of them I have taught the practice in case I die, others too will fall-in when they are ripe of age and maturity". "I have also taught four children of my bosom friends the profession and they are successful.

\section{F. Knowledge Stored in Brain}

This sub-category provides some responses from traditional medical practitioners about the knowledge managed or stored in the brain demonstrated by the following respondents: "Now if not because I have the knowledge stored in my head how will I be able to determine by mere holding a sick person's hand that he should be taken to hospital or not . How will I be able to determine that he needs drip or blood transfusion"."I have the knowledge of the practice in my head (by heart). I receive cure for treatments of diseases in my sleep mostly". Other respondents further gave example on asthmatic and jinnu sickness these are their story on their own words: "For asthmatic patients I pray for them and behold they will regain their selves again after which I ask them to visit a doctor for further medication and treatments. I do not possess documented source for the knowledge i possess. Jinn instruct me on how to administer root and herbs for treatment of diseases. The jinns could appear to me in my sleep or inform me as we are sited here of new medicine or method of cure to an ailment and you will not notice or understand whether I have communicated with them or not. However, I would like to document the knowledge because I would like to be remembered and also for the sake of my children and individuals that may wish to use it. 


\section{G. Procedures and Techniques of Preparing Traditional Medicine}

This category provides explanations quotes from the participants' responses on the procedure use in preparing traditional medicine by medical practitioners in Nigeria. It was generated from two sub-categories showing narratives about the ways traditional medicine are organized.

1. Experimentation and intellective skill.

2. Training on ethics and knowledge sharing

\section{H. Experimentation and Intellective Skills}

This sub-category contains description about the ways in which medical practitioner's prepared traditional medicine as mentioned by the following respondents: "We do conduct research in great detail to ascertain which concoction or medicine will best cure a disease, we also experiment what our predecessors had published and established". The respondents further said" we also read about 'dubbin naboyi' (medicine taught by prophet and messenger of Allah (SWT) Muhammad (SAW)) and learn more about what we practice." Another respondent voiced that: "We also used to consult Islamic documented source of Prophet Muhammad (SAW) on Islamic herbs for cure of diseases" Moreover, other respondents indicated that "we use to spend two weeks in the bush looking for these herbs and root". Similarly, some respondents explicated that "we send people (our family and relatives) to bush to pluck the herbs and root. I tell them their names, when they return I dry the ones that require drying and reserve others as primary aspects, while the secondary aspects cover washing, cleaning, drying, chopping, pounding, burning, cooking, packaging and preserving”.

\section{Training on Ethics and Knowledge Sharing}

According to responses from traditional medical practitioners, they were attend workshops /seminars to learn new ways or how to prepare traditional medicine as explained by the following respondent: we usually attended national workshop of traditional medical practitioners in Nigeria we discussed about working harder at administering medicine on deadly disease" Another interviewee ascertained that " $\mathrm{i}$ was even honored in one of the gatherings”.

Other respondent's interviewee ascertained that: "there is knowledge sharing from our elders (parents) they taught us about the way or how to prepare traditional medicine, so we use to share that knowledge among us" additionally, this respondent explained that: "there is knowledge sharing we receive from our senior scholars in which we have learnt about Jinns livelihood we have learnt that Jinn is conceived and delivered within eight (8) hours and spends two hundred (200) years suckling. The short lived ones spent ten thousand $(10,000)$ years".

\section{DISCUSSION OF FINDINGS}

\author{
A. Materials used for the Preparation of Traditional \\ Medicine by the Practitioners
}

Findings from this study indicated that, traditional medical practitioners in Nigeria have different materials which they use for the preparation of traditional medicine. Further investigation discovered that, Materials used in the preparation of traditional medicine has peculiarities based on cultural, social, traditional and religious beliefs. This is because some of the materials used in Matazu LGA as found out in this study included herbs, animal offal, Quranic verse, earth, and chicken which may not correlate with established and internationally recognized herbal materials. Findings also indicated that, some of the materials or ingredients used in the preparation of the medicine are related to each other, others are not. For examples a disease like dizziness and jinnu they used Qur'anic verses, chunk of tumpapiya tree, Baure herb, kuka and herbal perfume sprinkled burning charcoals, which are almost the same with ingredient used for disease like jinnu. While female infertility indicated that, prayer washed Qur'an verses, pumpkin seeds, sand maceration, magariyarkuka and karandapi are the ingredient use for this diseases treatment. Also another finding indicated that, there is no disease found in the study that have no treatment. Result from this study also shown that, The implication of some of the materials used such as earth remain a mystery in the world science that would require scientific investigation or laboratory experiments to uncover their medicinal values. This could also account for rejection of some of the herbal materials and perhaps formulas. However, as noted by the respondents they have recorded successes in their use.

\section{B. Type of knowledge Documentation Practices Employed by the Traditional Medical Practitioners}

Findings of this study revealed that documentation practices in Nigeria cover paper (manuscript), divine transmission and mental documentation of knowledge on and about traditional medical practices, published books on diseases and herbal cure, intrinsic detection of sickness typology this has to do with embedded knowledge in the brain of the practitioners; this knowledge is often transmitted via some spiritual or divine processes, hence the source is in the brain of the practitioners (mnemonics documentation). Detection allows the practitioner to know whether a sickness is treatable by him or not. This is done to avoid complications. Manuscript and knowledge inheritance are the only type of knowledge documented by traditional medical practitioners in the area of the study.

However, the results of this study also indicated that, the practitioners' used texts published by the traditional medical practitioners' leaders and the ones published by their members that contain explanations in great details. They don't give their books to voodoo practicing individuals because the books carry Quranic verses. Further 
investigation of the study revealed that, traditional medical practitioners have the knowledge in their brain as well as in written form which they personally penned down (manuscripts) in case of forgetfulness or something bad happens or death occurs to them. Findings also indicated that they have children who have taken after their footsteps and even prepares medicines. The result of this study also revealed that, some of the traditional medical practitioners have children and they have taught them the practice of the profession and they are successful. There was an indication that the traditional medical practitioners in Nigeria relied to a greater extent on published books from their associate outside the country as well as on their personal records (manuscripts), so the finding of study revealed that there was no formal documented information on traditional medical practices in the country, but they have intention to publish their methods of concoction for all the ailment and diseases as well as prescription and dosage. This is in line with Yakel \& Torres, 2003 Archival intelligence which proposes a first step in the formulation of a model defining the scope of information literacy for primary sources; the model seeks to change the current paradigm of "archival orientation" toward one focusing on archival information literacy.

\section{Procedures and Search skills used by Traditional Medical Practitioners in Preparing Traditional Medicine}

Finding from this study indicated that, experimentation, intellective skill, training on ethics and knowledge sharing are the procedures and search skills used by the traditional medical practitioners in preparing traditional medicine in the local government area. Findings also revealed that traditional medical practitioners conduct research in great detail to ascertain which concoction or medicine will best cure a disease, they experiment what their predecessors had published and established, they also read about 'dubbin naboyi' (medicine taught by prophet and messenger of Allah (SWT) Muhammad (SAW)) and learn more about what they practice. Following the procedures, findings from the study also indicated that traditional medical practitioners in this study visiting bushes, plucking of leaves, uprooting relevant plants for their stems and roots, cutting trees, and peeling of tree skins as primary aspect of the procedure while the secondary aspect covers washing, cleaning, drying, chopping, pounding, packaging and preserving. Others procedure included cooking and burning They also explained how to do concoction for ulcer, stomach ached, miscarriage sickness, female Infertility, stomach aches, pile disease, ulcer sickness, hiccup, tooth Ache, diabetes, hepatitis B, children skin disease (ela)”, Malaria, Headache, Gout, pile. Further investigation carried out in this study shown that traditional medical practitioners spend about two weeks in the bush looking for herbs and root. When they return from bush, they dry the ones that require drying using net to cover them so that spider and other insects will not infest them and keep the ones that don't require drying in separate rooms. It was also found out that; they don't dry them in the sun because it reduces the potent of the herbs.
Result from this study also indicated that sometimes they will receive spiritual revelation in the dreams whereby they will simply find themselves engaged in traditional medical discussions with some unknown individuals, they practical's what they discussed with them and it will yield good result. However, one respondent believed that his own search skill was divine. It is a belief that a source of inspiration was from the creator. In the earlier discussions, the researcher reported that some respondents revealed how they received instructions from Jinns on how to cure diseases or ailment, divine inspiration is exceptional because the source is Godly. Moving away from divine inspiration the last respondent said his own search skill was by learning and utilizing hereditary skills from his parents. He emphasizes the importance of continuous learning in traditional medicine because most of the knowledge and skills about the practice is not documented. Therefore learning plays a role in ensuring that knowledge is not lost due to redundancy or other reasons.

Additionally, further investigation in this study also indicated that, traditional medical practitioners used to attend national workshops of traditional medical practitioners in some of the Local Government in Katsina state where they discussed and share knowledge and experiences about administering medicine on deadly disease. Through this they gain a lot from their senior scholars.

\section{FINDINGS OF THE STUDY}

1. That the traditional medical practitioners in the Local Government Area use Biological- herbs, and special Quranic prayer. Another material worthy of note is the use of earth (sand).

2. That documentation practices employed by the traditional medical practitioners cover paper, divine transmission and mental documentation of knowledge on and about traditional medical practices. The documentation practices by the traditional practitioners are the production of unpublished. There is no formal documented information on traditional medicine but they have intention to publish their methods of concoction for all the ailments and diseases as well as prescriptions and dosages.

3. That the procedures and search skills used by the traditional medical practitioners included visiting bushes, plucking of leaves, uprooting relevant plants for their stems and roots, cutting trees, and peeling of tree skins as primary aspect of the procedure; while the secondary one covers washing, cleaning, drying, chopping, pounding, packaging and preserving. Others included cooking and burning. However, one respondent believed that her own search skill is divine.

\section{CONCLUSION}

The research work on An Assessment the Materials Used for the Preparation of Traditional Medicine by Traditional 
Medical Practitioners in Preparing Traditional Medicine in Nigeria was carried out successfully. It was concluded that participants are willing topublish their methods of concoction for the treatment of entire diseases as well as prescriptions and dosages so that people will benefit. It was also revealed there is no formal documented information on traditional medical practices in Nigeria Finally, for the successful documentation of traditional medical practices the Federal government needs to pay attention to the concerns raised by participants.

\section{RECOMMENDATIONS}

1. There is the need for the Traditional Medical Practitioner to focus on specific area of specialization for proper diagnosis and medication. This will help the practitioners to evenly grow in their practices in terms of learning how things are newly done which could only be achieved by focusing on specific area.

2. There is the need for the traditional medical practitioners to adopt scientific investigation or laboratory experiments to uncover their medicinal materials for the safety of the consumers. Governments have a responsibility for the health of their people and should strive to enforce national policies, regulations, and standards as part of comprehensive national health systems to ensure appropriate, safe and effective use of traditional medicine.

3. Access to documented information is essential because the public and relevant stakeholders will have increased understanding of preparations and concoctions for cure of diseases, for this there is the need for formal documentation of traditional medicinal knowledge as this may also improve the use of Traditional Medicine. In addition documenting Traditional Medical practice may help preserve knowledge. Today, the cultural survival of many indigenous communities is threatened, and some traditional systems of disseminating knowledge may already be lost. Modern lifestyles and the disruption of traditional ways of life may cause younger generations to lose interest in learning about traditional medicine. For these formal documentation on traditional medical knowledge and practice is very essential and it is the perfect way to preserve the knowledge for future generation.

4. Regular training, seminars and workshops should be organized by the traditional medical practitioners association and made mandatory to every member this will enable them to learn new procedures for preparing the traditional medicine and also serve as the medium of sharing knowledge/ ideas and experiences among themselves. The knowledge of traditional medicine, treatments and practices should be respected, preserved, promoted and communicated widely and appropriately.

5. There is the need for formal documented source of traditional medical information in which the members in need of traditional medical information could quickly use when the need arise, more so, modern tools such GSM hand set, CD and Audio/Video recorder should be employed in recording Information on all Traditional Medical Practices in order to provide access to the knowledge from variety of media. Traditional Medical Practitioners should have non-economic motivations for disseminating information, communication between conventional and traditional medicine providers should be strengthened and appropriate training programmes be established, it will serve as their medical information retrieval channel.

\section{REFERENCES}

[1] Abbott, A. (2014). Medical Student Attitudes toward Complementary, Alternative, and Integrative Medicine.

[2] Adam, L. (2008). Information and Communication Technologies, Knowledge Management and Indigenous knowledge: Implication to Livelihood of Communities in Ethiopia, from Lishan@cffd.net on $15 / 09 / 2008$.

[3] Akintilo, A.A.A. (2000). Information and Communication Patterns in Traditional Medical Practice in South-Western Nigeria and Interface with National Health Information System. Doctoral Thesis, Africa Regional Centre for Information Science, University of Ibadan, Nigeria.

[4] Denzin, N. K. \& Lincoln, Y. S. (2003). Introduction: The Discipline and Practice of qualitative research. In: N.K. Denzin \&Y.S. Lincoln (Eds.), The Landscape of Qualitative Research. Theories and Issues, 1-45, Thousand Oaks: Sage Publications.

[5] Madauci, I., Yahaya, I. \& Bello, D. (2008). Hausa Customs, Zaria: States of Northern Nigerian Publishing Company.

[6] Olowu, K. (2004). Access to Information: Myths and Realities, Nigerian Libraries and documentation Centers, 38(1), 48-55.

[7] Battiste, M., \& Henderson, J. Y. (2000). Protecting Indigenous Knowledge and Heritage. Saskatoon, Saskatchewan: Purich Publishing.

[8] Hassan, M. A. (2013). Research Population. Retrieved January 16, 2016 from https://www.academia.edu/5563491/Research_ Population.

[9] Niezen, R. (2003). The Origins of Indigenism: Human Rights and the Politics of Identity. Los Angeles: University of California Press.

[10] Ocholla, D. (2007). Marginalized Knowledge: An Agenda for Indigenous Knowledge Development and Integration with Other Forms of Knowledge. 